\title{
Clinical evaluation of a newly developed graft inserter (NS Endo-Inserter) for Descemet stripping automated endothelial keratoplasty
}

This article was published in the following Dove Medical Press journal:

Clinical Ophthalmology

\author{
Takeshi Soma' \\ Shizuka Koh',2 \\ Yoshinori Oie' \\ Kazuichi Maruyama ${ }^{1,2}$ \\ Motokazu Tsujikawa' \\ Satoshi Kawasaki' \\ Naoyuki Maeda' \\ Kohji Nishida' \\ 'Department of Ophthalmology, \\ Osaka University Graduate \\ School of Medicine, Suita, Osaka, \\ Japan; ${ }^{2}$ Department of Innovative \\ Visual Science, Osaka University, \\ Graduate School of Medicine, Suita, \\ Osaka, Japan
}

\begin{abstract}
Purpose: The aim of this study was to describe the postoperative outcomes of Descemet stripping automated endothelial keratoplasty (DSAEK) performed using our newly developed graft inserter (NS Endo-Inserter) and compare the findings with those for DSAEK performed using the Busin glide.
\end{abstract}

Patients and methods: In this retrospective, case-control, institutional study, we studied the clinical outcomes of DSAEK performed using the NS Endo-Inserter (NS group, $n=13$ ) or the Busin glide (Busin group, $\mathrm{n}=10$ ) for patients with corneal endothelial dysfunction. Clinical parameters, including the distance-corrected visual acuity (DCVA), endothelial cell (EC) loss, and intraoperative/postoperative complications, were assessed over a 6-month follow-up period. Results: At 6 months after surgery, the mean DCVA showed no significant difference between the two groups. EC loss at 3 and 6 months after DSAEK was $9.1 \% \pm 20.7 \%$ and $18.2 \% \pm 22.6 \%$, respectively, in the NS group and $44.0 \% \pm 25.5 \%$ and $46.5 \% \pm 23.3 \%$, respectively, in the Busin group; differences between groups were statistically significant at both 3 and 6 months $(P=0.024$ and $P=0.016$, respectively). Anterior chamber hemorrhage was observed in one patient in the Busin group. Rebubbling after surgery was required for one eye in the Busin group. No complications were observed in the NS group.

Conclusion: Our newly developed graft inserter for DSAEK may cause significantly less EC damage than the conventional pull-through technique using the Busin glide. Our inserter permits safe endothelial graft delivery without anterior chamber collapse and can result in successful graft attachment without complications at 6 months after surgery.

Keywords: corneal endothelial transplantation, clinical evaluation of new technique, endothelial cell damage, graft attachment, safety

\section{Introduction}

Bullous keratopathy is a pathological condition characterized by corneal stromal edema with epithelial bullae due to cell loss and endothelial decompensation. Most commonly, it occurs because of Fuchs' corneal endothelial dystrophy or cataract surgery. In the past, the only available treatment option was penetrating keratoplasty (PK). In recent years, Descemet stripping automated endothelial keratoplasty (DSAEK) has been the mainstay of surgical management for bullous keratopathy, because it allows faster and more stable recovery than does PK. ${ }^{1}$ The pull-through technique is a standard method for DSAEK, with Busin glide insertion being one of the most popular procedures. ${ }^{2}$ However, endothelial cell (EC) loss, particularly in the early postoperative period, ${ }^{3-5}$ remains a limitation of DSAEK. For Asian eyes, in particular, shallower anterior
Department of Ophthalmology, Osaka University Graduate School of Medicine, Room E7, 2-2 Yamadaoka, Suita, Osaka 565-087I, Japan

Tel +8I 668793456

Fax +8I 668793458

Email knishida@ophthal.med.osaka-u.ac.jp 
chambers and narrower angles result in difficulties during graft tissue manipulation, which may directly contribute to EC loss and damage. ${ }^{6-8}$

To minimize intraoperative mechanical stress on the graft, we recently developed a new graft inserter (NS EndoInserter; Hoya Surgical Optics, Tokyo, Japan), which enables single-step insertion of corneal graft tissue into the anterior chamber, on the basis of a pressure-flow concept instead of the pull-through concept. ${ }^{9}$ We also evaluated the very early outcomes of DSAEK performed using this new graft inserter in human eyes and found that the procedure was successful and uneventful. ${ }^{9}$ However, clinical evaluations during the postoperative period had not been performed.

Therefore, in this study, we investigated the early postoperative outcomes of DSAEK performed using our newly developed NS Endo-Inserter and compared the 6-month outcome of this procedure with that of DSAEK performed using the Busin glide.

\section{Materials and methods}

This retrospective case-control study was reviewed and approved by the institutional review board of Osaka University Hospital. All participants provided written informed consent after receiving an explanation of the nature and risks/benefits of study participation. All study protocols adhered to the tenets of the Declaration of Helsinki.

\section{Patient population}

We enrolled 13 eyes of 13 consecutive patients with corneal endothelial dysfunction, who underwent DSAEK using the NS Endo-Inserter at Osaka University Hospital between July 2016 and March 2017, with a subsequent follow-up of at least 6 months (NS group). Because we routinely use the NS Endo-Inserter as a standard tool for DSAEK at present, we compared the clinical outcomes for the NS group with those for 10 eyes of 10 patients with corneal endothelial dysfunction, who underwent DSAEK using the Busin glide (5.0 mm Busin spatula; \#19098; Moria, Doylestown, PA, USA) between October 2010 and February 2012, when the NS Endo-Inserter was not yet being used (Busin group). The demographic and clinical characteristics of patients in both groups are shown in Table 1. Before surgery, all patients underwent a complete ophthalmological examination.

\section{NS Endo-Inserter}

The NS Endo-Inserter consists of a main body and a flexible platform at its front end. A movable cartridge is attached to the main body, along with a valved conduit. A $2.5 \mathrm{~mL}$ syringe, which is filled with balanced salt solution (BSS) before surgery, is continuous with the body of the inserter (Figure 1). The DSAEK graft is placed onto the platform, with ECs facing upward (Figure 2A and B). Then, the flexible platform and graft are drawn within the inserter via steady forward movement of the cartridge (Figure $2 \mathrm{C}$ and $\mathrm{D}$ ), which is achieved by using the valved conduit. By gentle depression of the syringe plunger, the graft and BSS are then delivered into the anterior chamber through a premade $4.6 \mathrm{~mm}$ incision (Figure 2E and F). The closed system prevents anterior chamber collapse during corneal graft delivery.

Table I Clinical and demographic characteristics of patients who received Descemet stripping automated endothelial keratoplasty using the NS-Endo inserter (NS group) or the Busin glide (Busin group)

\begin{tabular}{|c|c|c|}
\hline & NS group $(n=13)$ & Busin group $(n=10)$ \\
\hline & Mean \pm SD & Mean \pm SD \\
\hline Age (years) & $74.1 \pm 10.4$ & $67.6 \pm 15.6$ \\
\hline Sex (male/female) & $9 / 4$ & $3 / 7$ \\
\hline Preoperative corneal thickness $(\mu \mathrm{m})$ & $775 \pm 149$ & $801 \pm 169$ \\
\hline Preoperative DCVA (logMAR) & $1.25 \pm 0.62$ & $1.20 \pm 0.49$ \\
\hline \multicolumn{3}{|l|}{ Indications for surgery, n (\%) } \\
\hline Pseudophakic bullous keratopathy & $4(31)$ & 0 \\
\hline Fuchs' corneal endothelial dystrophy & $2(15)$ & $3(30)$ \\
\hline Argon laser iridotomy-induced bullous keratopathy & $\mathrm{I}(8)$ & $2(20)$ \\
\hline After intraocular surgery & $\mathrm{I}(8)$ & $2(20)$ \\
\hline Exfoliation syndrome & $3(23)$ & $I(10)$ \\
\hline Cytomegalovirus endotheliitis & $2(23)$ & $I(10)$ \\
\hline Failed PK & 0 & $\mathrm{I}(\mathrm{I0})$ \\
\hline \multicolumn{3}{|l|}{ Other comorbidities } \\
\hline Glaucoma (history of previous trabeculectomy) & $7(7)$ & $3(2)$ \\
\hline Macular diseases & 3 & 2 \\
\hline Diabetic retinopathy & 2 & 0 \\
\hline
\end{tabular}

Abbreviations: DCVA, distance-corrected visual acuity; logMAR, logarithm of the minimum angle of resolution; PK, penetrating keratoplasty. 


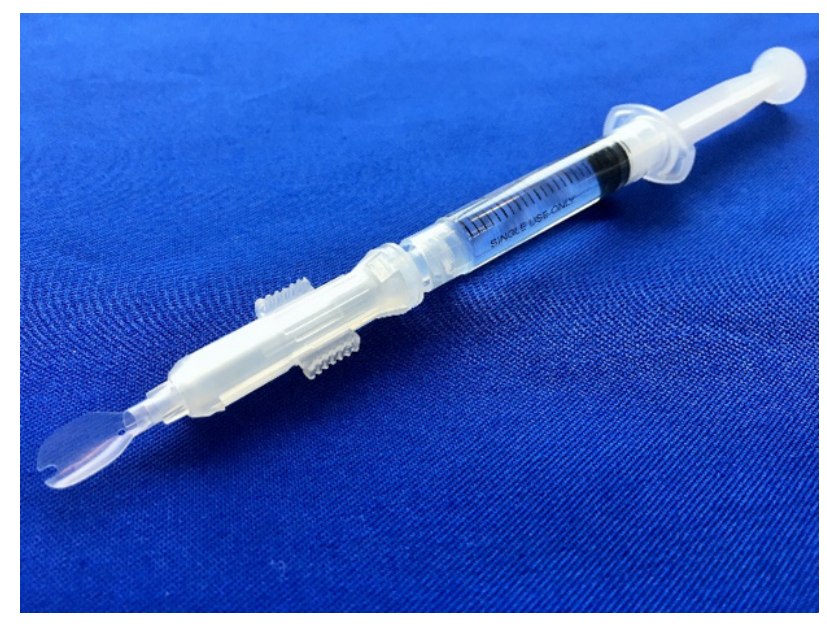

Figure I The NS Endo-Inserter developed for graft insertion during Descemet stripping automated endothelial keratoplasty.

\section{Surgical technique}

All DSAEK procedures were performed by one of the two surgeons (TS and $\mathrm{KN}$ ) using our standard technique, as previously described. ${ }^{9}$ In brief, precut donor corneas (target thickness, 100-120 $\mu \mathrm{m}$ ) provided by SightLife Eye Bank (Seattle, WA, USA) were used for all cases. After the anterior chamber maintainer was set up, the Descemet membrane and endothelium were stripped from the recipient's central cornea (this step is omitted in non-DSAEK [nDSAEK] cases). ${ }^{8}$ An inferior peripheral iridectomy was then created using a $25 \mathrm{G}$ vitreous cutter, and two bent incisions were placed. The donor graft was delivered through the temporal incision using either the NS Endo-Inserter or Busin glide. ${ }^{2}$ The incision length was $4.6 \mathrm{~mm}$ for the NS Endo-Inserter and $5.0 \mathrm{~mm}$ for the Busin glide. After graft delivery into the anterior chamber, an air tamponade was created to ensure good graft-host apposition. All patients were instructed to remain in an upward-facing position on their beds for 3 hours after surgery.

\section{Postsurgical regimen and evaluation}

After surgery, the patients received a combination of antibiotics (Cravit ${ }^{\circledR} 1.5 \%$; Santen Pharmaceutical Co., Ltd., Osaka, Japan) and corticosteroid drops (Rinderon ${ }^{\circledR} 0.1 \%$; Shionogi \& Co., Ltd., Osaka, Japan) four times daily for 12 months, with slow dose tapering to twice daily over 36 months. All patients were evaluated at 1 day, 1 week, 1 month, and 3 months after surgery, followed by evaluations every 3 months thereafter. Evaluations included DCVA measurement and slit-lamp examination. DCVA was measured using the Landolt $\mathrm{C}$ chart, and decimal DCVA values were converted to logarithm of the minimum angle of resolution (logMAR) units for statistical analyses. Specular microscopy images were obtained using a non-contact specular microscope (SP-3000P; Topcon, Tokyo, Japan) at the 3-month and 6-month visits. Intraoperative complications, such as iatrogenic primary graft failure and donor dislocation requiring rebubbling, and postoperative complications, were also recorded.

\section{Statistical analyses}

Data are presented as mean $\pm \mathrm{SD}$. The Mann-Whitney $U$ test was used to compare demographic/clinical data between the NS and Busin groups. All statistical analyses were performed using JMP software (JMP Version 12.2.0; SAS Institute Inc., Cary, NC, USA). A $P$-value of $<0.05$ was considered statistically significant.
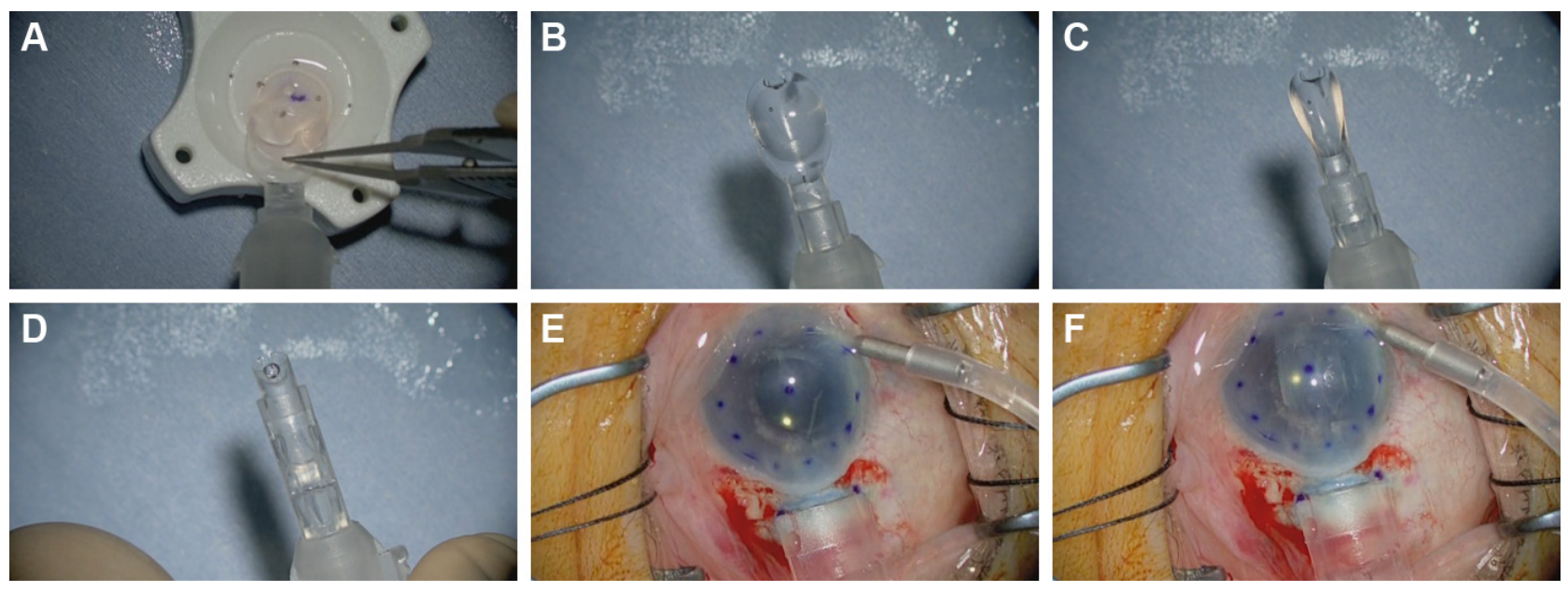

Figure 2 Endothelial graft lenticule delivery using the NS Endo-Inserter.

Notes: (A and B) The precut graft is placed onto the platform of NS Endo-Inserter with the endothelial side facing upward. (C and D) The flexible platform and graft are drawn within the inserter body via steady forward movement of the cartridge. (E) The nozzle of the inserter is inserted through the temporal incision. (F) The graft is delivered into the anterior chamber through the incision by gentle depression of the syringe plunger. 


\section{Results}

Corneal edema was cleared in all patients. A representative case of a 50-year-old woman with Fuchs' corneal endothelial dystrophy, who underwent DSAEK using the NS EndoInserter, is shown in Figure 3. Preoperative and postoperative visual acuity data for both groups are shown in Table 2 . There was no significant difference in the mean DCVA between the two groups before $(P=0.830)$ and at 6 months after surgery $(P=0.860)$. Preoperative and postoperative EC density values and EC loss percentages for both groups are shown in Table 3. The preoperative mean EC density was significantly higher in the Busin group $\left(2,904 \pm 208\right.$ cells $\left./ \mathrm{mm}^{2}\right)$ than in the NS group $\left(2,664 \pm 199\right.$ cells $\left./ \mathrm{mm}^{2} ; P=0.008\right)$. At 3 months after surgery, the mean EC density was 2,397 \pm 554 cells $/ \mathrm{mm}^{2}$ (range, $1,027-2,966$ cells $/ \mathrm{mm}^{2}$ ) in the NS group and $1,679 \pm 819$ cells $/ \mathrm{mm}^{2}$ (range, $741-3,146$ cells $/ \mathrm{mm}^{2}$ ) in the Busin group. Thus, the EC loss was $9.1 \% \pm 20.7 \%$ in the NS group and $44.0 \% \pm 25.5 \%$ in the Busin group, with a significant difference between groups $(P=0.024)$. However, the EC density was not significantly different between groups $(P=0.110)$. At 6 months after surgery, the mean EC density was 2,176 \pm 597 cells $/ \mathrm{mm}^{2}$ (range, 1,154-3,277 cells $/ \mathrm{mm}^{2}$ ) in the NS group and $1,552 \pm 668$ cells $/ \mathrm{mm}^{2}$ (range, $882-2,660$ cells $/ \mathrm{mm}^{2}$ ) in the Busin group. Thus, the EC loss was $18.2 \% \pm 22.6 \%$ in the NS group and $46.5 \% \pm 23.3 \%$ in the Busin group; both the EC density and loss showed a significant difference between groups ( $P=0.047$ and 0.016 , respectively).

There were no intraoperative complications in the NS group. All grafts were successfully delivered into the anterior chamber without causing it to collapse. In addition, no postoperative complications, including primary graft failure or graft dislocation, were observed in this group. In the Busin group, intraoperative hyphema developed in one eye, whereas another eye required rebubbling for graft attachment after surgery.

\section{Discussion}

In this study, we evaluated the clinical outcomes of DSAEK performed using our newly developed graft inserter, the NS Endo-Inserter, and compared the findings with those for DSAEK performed using the Busin glide. Our results showed that the use of the NS Endo-Inserter remarkably minimized EC loss at 6 months after DSAEK because it allows smooth graft insertion without anterior chamber collapse.

DSAEK has replaced PK as the gold standard surgical treatment for patients with corneal endothelial dysfunction. In recent years, endothelial keratoplasty has dramatically evolved. A number of new surgical techniques or devices have been modified to avoid complications and minimize EC loss after DSAEK, and techniques such as folding and grasping the donor tissue with forceps or the pull-through technique using glides have been popular. Graft insertion devices can be categorized into three groups on the basis of their injection mechanism as follows: folding, pull-through (glides), and push-in (inserters) devices. ${ }^{10}$ The NS EndoInserter used in this study is a push-in device.

According to previous studies, the mean amount of EC loss at 6 months after surgery performed using the Busin glide ranges from $20 \%$ to $47.5 \%$. $^{2,11-15}$ The high EC loss percentage for the Busin group (46.5\% at 6 months) in this study was similar to the value reported by Gangwani et al, ie, $47.5 \%$ at 6 months (30 eyes). ${ }^{12}$ This increased EC loss can partly be attributed to the fact that all our patients were Asian; in this population group, the surgical procedure tends to be challenging because of characteristically smaller eyes and
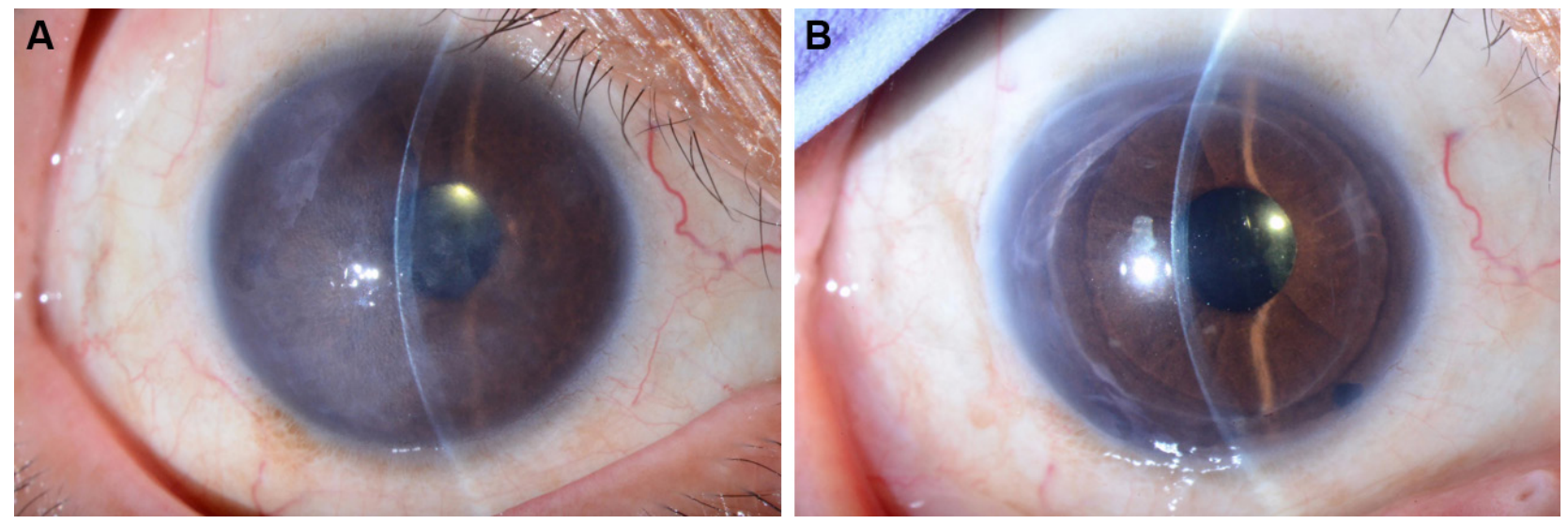

Figure 3 Pre- (A) and postoperative (B) slit-lamp photographs of a representative patient, a 50-year-old woman with Fuchs' corneal endothelial dystrophy, who underwent DSAEK using NS Endo-Inserter.

Note: At 6 months after surgery, postoperative endothelial cell density was 2,602 cells $/ \mathrm{mm}^{2}$ and DCVA was I.0.

Abbreviations: DCVA, distance-corrected visual acuity; DSAEK, Descemet stripping automated endothelial keratoplasty. 
Table 2 DCVA before and after Descemet stripping automated endothelial keratoplasty performed using the NS-Endo inserter (NS group) or the Busin glide (Busin group)

\begin{tabular}{|c|c|c|c|}
\hline & NS group $(n=13)$ & Busin group $(n=10)$ & $P$-value \\
\hline & Mean \pm SD & Mean \pm SD & \\
\hline Preoperative DCVA (logMAR) & $1.25 \pm 0.62$ & $1.20 \pm 0.49$ & 0.830 \\
\hline DCVA at 6 months after surgery (logMAR) & $0.55 \pm 0.45$ & $0.58 \pm 0.49$ & 0.860 \\
\hline
\end{tabular}

Abbreviations: DCVA, distance-corrected visual acuity; logMAR, logarithm of the minimum angle of resolution.

shallower anterior chambers. Nevertheless, the amount of EC loss in the NS group (18.2\% at 6 months) was significantly lower than that in the Busin group. Because all surgeries for the Busin group were performed before those for the NS group, we cannot rule out the fact that a learning curve for DSAEK could have resulted in decreased EC loss in the NS group. However, both surgeons have been using the Busin glide during DSAEK for several years. According to a study evaluating the use of the EndoGlide (AngioTech, Reading, Pennsylvania, USA/Network Medical Products, North Yorkshire, UK) pull-through device, for 20 Asian eyes, the mean EC loss was $13.1 \%$ at 6 months. ${ }^{16}$ Another study reported that EC loss at 6 months was $25.8 \%$ for non-Asian eyes treated using the EndoGlide. ${ }^{12}$ Thus, a comparison of the NS EndoInserter with the EndoGlide would yield interesting results.

At present, there are two commercially available push-in graft inserters other than the NS Endo-Inserter: the Neusidl Corneal Inserter (Fischer Surgical, Arnold, MO, USA) and the EndoSerter (Ocular Systems, Winston-Salem, NC, USA). The reported mean EC loss with the Neusidl Corneal Inserter was $33.1 \%$ at 6 months after surgery for 48 eyes, ${ }^{17}$ while that with the EndoSerter used for 10 eyes was 30\% at 6 months and $31 \%$ at 12 months after surgery. ${ }^{18}$ In comparison, our NS Endo-Inserter resulted in a higher EC density in the graft cornea at 6 months after DSAEK. Longer follow-up periods are needed to clarify the efficacy of the NS Endo-Inserter.

DCVA showed no significant difference between the two groups at 6 months after surgery in this study. While it improved in the majority of cases in both groups, there was no improvement in some cases, because of the presence of other comorbidities. To date, the insertion technique has not influenced the visual outcome, unless the procedure was extremely traumatic. ${ }^{12,13} \mathrm{We}$ recently reported that the postoperative morphology of the anterior corneal surface and the venting incision inside the pupil area are important factors affecting the visual outcome after DSAEK. ${ }^{19}$ In this study, we confirmed that all venting incisions were placed outside the pupil area, regardless of whether the NS Endo-Inserter or the Busin glide was used.

This study highlights the safety of our newly developed NS Endo-Inserter for graft delivery, which minimizes intraoperative mechanical stress on the graft tissue. Seven of the 13 eyes $(53 \%)$ in the NS group had received trabeculectomy before DSAEK. It is suggested that special attention is necessary for the safe and effective performance of DSAEK, particularly in eyes with a history of glaucoma surgery. ${ }^{20}$ There was no postoperative complication in the NS group in this study, at least during the first 6 months after surgery. Although there are contradictory reports about the correlation between previous trabeculectomy and post-DSAEK complications, an increased risk of secondary graft failure in eyes with a history of trabeculectomy has been reported. ${ }^{21,22}$ Therefore, long-term observation is necessary to clarify the efficacy and safety of this device.

This study has some limitations. First, it had a retrospective design, and second, it involved a small sample size. Third, a learning curve for DSAEK could have affected the surgical procedures performed in the later years. Future studies with

Table 3 Pre- and postoperative EC density and postoperative EC loss in eyes that underwent Descemet stripping automated endothelial keratoplasty using the NS-Endo inserter (NS group) or the Busin glide (Busin group)

\begin{tabular}{|c|c|c|c|}
\hline & NS group $(n=13)$ & Busin group $(n=10)$ & $P$-value \\
\hline & Mean \pm SD & Mean \pm SD & \\
\hline Preoperative EC density (cells $/ \mathrm{mm}^{2}$ ) & $2,664 \pm 199$ & $2,904 \pm 208$ & 0.008 \\
\hline EC density at 3 months after surgery (cells $/ \mathrm{mm}^{2}$ ) & $2,397 \pm 554$ & $1,679 \pm 819$ & 0.110 \\
\hline EC loss at 3 months after surgery (\%) & $9.1 \pm 20.7$ & $44.0 \pm 25.5$ & 0.024 \\
\hline EC density at 6 months after surgery (cells $/ \mathrm{mm}^{2}$ ) & $2,176 \pm 597$ & $1,552 \pm 668$ & 0.047 \\
\hline EC loss at 6 months after surgery (\%) & $18.2 \pm 22.6$ & $46.5 \pm 23.3$ & 0.016 \\
\hline
\end{tabular}

Abbreviation: $\mathrm{EC}$, endothelial cell. 
a larger patient population and a longer follow-up period are warranted for further clarification of our findings.

\section{Conclusion}

Our findings suggest that DSAEK performed using our newly developed NS Endo-inserter causes significantly less EC damage at 6 months after surgery than does DSAEK performed using the pull-through technique with the Busin glide. The former procedure permits safe endothelial graft delivery without anterior chamber collapse and can result in successful graft attachment without complications by 6 months after the procedure.

\section{Author contributions}

All the authors participated sufficiently in the work to take public responsibility for appropriate portions of the content. All authors contributed to data analysis, drafting and revising the article, gave final approval of the version to be published, and agree to be accountable for all aspects of the work.

\section{Disclosure}

Dr Soma and Dr Nishida, in conjunction with Hoya Surgical Optics, Japan, have filed for a worldwide patent (code PCT/ JP2011/067665 and PCT/JP2015/055624) for the one-step corneal graft delivery system described in this manuscript. The authors report no other conflicts of interest in this work.

\section{References}

1. Tan DT, Dart JK, Holland EJ, Kinoshita S. Corneal transplantation. Lancet. 2012;379(9827):1749-1761.

2. Busin M, Bhatt PR, Scorcia V. A modified technique for descemet membrane stripping automated endothelial keratoplasty to minimize endothelial cell loss. Arch Ophthalmol. 2008;126(8):1133-1137.

3. Lee WB, Jacobs DS, Musch DC, Kaufman SC, Reinhart WJ, Shtein RM. Descemet's stripping endothelial keratoplasty: safety and outcomes: a report by the American Academy of Ophthalmology. Ophthalmology. 2009;116(9):1818-1830.

4. Cornea Donor Study Investigator Group, Lass JH, Gal RL, et al. Donor age and corneal endothelial cell loss 5 years after successful corneal transplantation. Specular microscopy ancillary study results. Ophthalmology. 2008;115(4):627-632.

5. Price MO, Fairchild KM, Price DA, Price FW. Descemet's stripping endothelial keratoplasty five-year graft survival and endothelial cell loss. Ophthalmology. 2011;118(4):725-729.
6. Shimazaki J, Amano S, Uno T, Maeda N, Yokoi N; Japan Bullous Keratopathy Study Group. National survey on bullous keratopathy in Japan. Cornea. 2007;26(3):274-278.

7. Ang LP, Higashihara H, Sotozono C, et al. Argon laser iridotomyinduced bullous keratopathy a growing problem in Japan. $\mathrm{Br} J$ Ophthalmol. 2007;91(12):1613-1615.

8. Kobayashi A, Yokogawa H, Sugiyama K. Non-Descemet stripping automated endothelial keratoplasty for endothelial dysfunction secondary to argon laser iridotomy. Am J Ophthalmol. 2008;146(4):543-549.

9. Soma T, Koh S, Maeda N, Mitomo K, Quantock AJ, Nishida K. New graft insertion device for Descemet stripping automated endothelial keratoplasty. Cornea. 2017;36(11):1432-1436.

10. Khan SN, Shiakolas PS, Mootha VV. Descemet's stripping automated endothelial keratoplasty tissue insertion devices. JOphthalmic Vis Res. 2015;10(4):461-468.

11. Busin M, Scorcia V. A prospective study comparing EndoGlide and Busin glide insertion techniques in descemet stripping endothelial keratoplasty. Am J Ophthalmol. 2012;154(2):416-417.

12. Gangwani V, Obi A, Hollick EJ. A prospective study comparing EndoGlide and Busin glide insertion techniques in descemet stripping endothelial keratoplasty. Am J Ophthalmol. 2012;153(1):38-43.

13. Bahar I, Kaiserman I, Sansanayudh W, Levinger E, Rootman DS. Busin guide vs forceps for the insertion of the donor lenticule in Descemet stripping automated endothelial keratoplasty. Am J Ophthalmol. 2009;147(2):220-226.

14. Masaki T, Kobayashi A, Yokogawa H, Saito Y, Sugiyama K. Clinical evaluation of non-Descemet stripping automated endothelial keratoplasty (nDSAEK). Jpn J Ophthalmol. 2012;56(3):203-207.

15. Nakagawa $H$, Inatomi $T$, Hieda $O$, et al. Clinical outcomes in descemet stripping automated endothelial keratoplasty with internationally shipped precut donor corneas. Am J Ophthalmol. 2014;157(1):50-55.

16. Khor WB, Mehta JS, Tan DT. Descemet stripping automated endothelial keratoplasty with a graft insertion device: surgical technique and early clinical results. Am J Ophthalmol. 2011;151(2):223-232.e2.

17. Terry MA, Straiko MD, Goshe JM, et al. Endothelial keratoplasty: prospective, randomized, masked clinical trial comparing an injector with forceps for tissue insertion. Am J Ophthalmol. 2013;156(1):61-68.

18. Elbaz U, Yeung SN, Lichtinger A, et al. EndoGlide versus EndoSerter for the insertion of donor graft in descemet stripping automated endothelial keratoplasty. Am J Ophthalmol. 2014;158(2):257-262.

19. Iwama $Y$, Soma $T$, Maeda N, et al. Factors limiting the visual outcome after Descemet stripping automated endothelial keratoplasty: Comprehensive analysis including the graft position and irregularity. Cornea. 2018;37(1):20-27.

20. Banitt MR, Chopra V. Descemet's stripping with automated endothelial keratoplasty and glaucoma. Curr Opin Ophthalmol. 2010;21(2): 144-149.

21. Aldave AJ, Chen JL, Zaman AS, Deng SX, Yu F. Outcomes after DSEK in 101 eyes with previous trabeculectomy and tube shunt implantation. Cornea. 2014;33(3):223-229.

22. Anshu A, Price MO, Price FW. Descemet's stripping endothelial keratoplasty: long-term graft survival and risk factors for failure in eyes with preexisting glaucoma. Ophthalmology. 2012;119(10):1982-1987.
Clinical Ophthalmology

\section{Publish your work in this journal}

Clinical Ophthalmology is an international, peer-reviewed journal covering all subspecialties within ophthalmology. Key topics include: Optometry; Visual science; Pharmacology and drug therapy in eye diseases; Basic Sciences; Primary and Secondary eye care; Patient Safety and Quality of Care Improvements. This journal is indexed on Submit your manuscript here: http://www.dovepress.com/clinical-ophthalmology-journal

\section{Dovepress}

PubMed Central and CAS, and is the official journal of The Society of Clinical Ophthalmology (SCO). The manuscript management system is completely online and includes a very quick and fair peer-review system, which is all easy to use. Visit http://www.dovepress.com/ testimonials.php to read real quotes from published authors. 